\title{
Editorial
}

\section{Brasil: Incertezas, injustiças e resistências}

\author{
Luciano Zanetti Pessôa Candiotto
}

Enfim, o inesquecível e lastimável ano de 2020 está terminando! Um ano que entrará mundialmente para os livros de História. Um ano em que, em algum momento, todas as pessoas pararam fisicamente, devido ao isolamento social, para se evitar a disseminação do coronavírus e da COVID-19; mas, também, pararam para refletir sobre nossa fragilidade enquanto indivíduos e enquanto humanidade.

O quão 2020 afetará a vida de cada um daqui para frente, isso é muito relativo e incerto. Do ponto de vista econômico, ambiental e geopolítico global, certamente, haverá profundas mudanças, sobretudo no médio e longo prazos. Porém, do ponto de vista individual, tudo é muito relativo, pois são as ações e a mentalidade de cada pessoa que podem, ou não, mudar. Assim, o futuro se torna algo ainda mais incerto.

Este editorial começa abordando essa questão, pelo fato de 2020 não ter sido um ano qualquer. Nosso cotidiano foi alterado (trabalho, lazer, relações familiares, relações sociais etc.) e a própria percepção sobre o espaço e o tempo, provavelmente, serão alteradas a partir de agora. Porém, para além de nossa percepção enquanto indivíduos, do ponto de vista objetivo e material, o espaço geográfico, o espaço social, o ambiente e a sociedade, não são e não serão os mesmos. Quem viver, verá!

A crise civilizatória, propagada e discutida há algumas décadas, sobretudo a partir da década de 1990, se manifesta muito potente. Aquilo que, há alguns anos, poderíamos imaginar que não aconteceria ou que demoraria para acontecer, como vivenciar "na 
pele" as consequências do aquecimento do planeta; a expansão do ódio, da violência, da fome e das desigualdades sociais; a ascensão meteórica de discursos e de práticas fascistas e xenofóbicos, fundamentada na negação da ciência, do respeito e do diálogo; o foco puramente no presente e a negligência em relação ao futuro, sobretudo a um "futuro comum", vem mais e mais acontecendo. E haverá saída para essa crise?

Como não me cabe prever o futuro, deixo, aqui, essas questões, e parto para relatar, brevemente, algumas evidências do presente, com ênfase no Brasil, na escala nacional. Em primeiro lugar, cabe lembrar que um país, uma "nação", uma "pátria”, são construções sociais. Como insistem vários autores, toda escala é construída socialmente. Mas no caso de um Estado-nação, tão enfatizado por Ratzel, essa construção implica profundas intencionalidades políticas e ideológicas. O que é um país, uma "pátria", uma "nação"? Para responder a essas questões, é preciso remeter aos elementos históricos de criação de um país e aos discursos de defesa da "pátria". Mas não há pretensão de se fazer isso aqui.

Ao aceitar que vivemos em um país chamado Brasil, e ao enfatizar o que ocorreu nesse país em 2020, é possível delinear alguns elementos fundamentais para confirmar a hipótese de que, para além da COVID-19 e das mais de 180 mil mortes por aqui (estas linhas são escritas em meados de dezembro de 2020), muitas tragédias aconteceram no território brasileiro nesse ano. Algumas delas, são, de alguma forma, relatadas neste número de AMBIENTES. Outras, provavelmente, ainda serão, haja vista as consequências que 2020 e 2021 ainda trarão aos nossos ecossistemas, agrossistemas e ambientes urbanos e rurais.

Além da negligência do atual Presidente do Brasil, grande "defensor da pátria", em relação à gravidade da COVID-19, através de discursos infelizes, piadas e manifestações públicas que somente atrapalharam o combate ao vírus, 2020 foi o ano em que "a boiada começou a passar" com uma força inaudita, sobretudo em virtude da conivência do atual Ministro do Meio Ambiente; seja ao enfraquecer ou eliminar o processo de fiscalização ambiental e possíveis punições aos criminosos ambientais (do desmatamento, 
das queimadas, da regularização ambiental etc.), seja ao iniciar um amplo processo de desregulamentação e desmonte de normas e políticas ambientais. Os exemplos nesse sentido são vários. Enfraquecimento de instituições (IBAMA, ICMBIO, entre outras), de fóruns como o Conselho Nacional do Meio Ambiente (CONAMA), redução de verbas para a preservação, conservação, combate aos incêndios - entre outras barbaridades, exemplos de impunidade.

Mas não foi somente o Ministro do Meio Ambiente. O tratamento do atual governo federal com outras questões (educação, saúde, direitos humanos, combate ao crime etc.), com destaque para a questão agrária, envolvendo o compromisso governamental com o fortalecimento de um estilo de produção agropecuário pautado na exploração máxima de recursos naturais e na degradação ambiental (vide a ampla liberalização de agrotóxicos e organismos transgênicos), afetando a biodiversidade brasileira e grupos historicamente marginalizados (indígenas, camponeses, quilombolas, sem-terra, entre outros), tem sido desastroso. Em benefício de latifundiários, ruralistas, políticos e empresas vinculados ao chamado agronegócio, o povo e o território brasileiros estão pagando um alto preço, com consequências incalculáveis.

O massacre de indígenas, vinculado à violência intencional de muitos "defensores da pátria" e ao abandono dessas populações frente à expansão da COVID-19; o recorde de queimadas na Amazônia, no Pantanal e no Cerrado; os cortes de incentivos, créditos e de políticas públicas para camponeses, sobretudo no que tange à agroecologia (tema do dossiê contido neste número), contrastado com a ampliação de recursos e benefícios ao agronegócio, são alguns exemplos marcantes da situação de calamidade vivenciada no espaço agrário do país.

Já nas cidades, a violência contra pobres e negros é aguçada. Preconceitos, espancamentos e assassinatos contra pessoas inocentes ampliam o quadro de injustiça ambiental/social no Brasil. E a impunidade tem sido outra marca deste atual (des)governo. Infelizmente, é possível dizer que a vida tem sido cada vez mais banalizada. As mortes 
por COVID-19, por ódio, abuso de poder e intolerância têm sido naturalizadas. Por outro lado, as lutas por justiça ambiental (e social) são necessárias e urgentes.

Apesar de existirem resistências, as dificuldades são enormes e tendem a ser cada vez maiores!

O presente número de AMBIENTES: Revista de Geografia e Ecologia Política traz um dossiê sobre agroecologia, um tema de interesse crescente, mas também permeado por ataques e questionamentos por parte dos defensores da "moderna" agricultura capitalista, mais conhecida como agronegócio. Mas por que a agroecologia, que é ínfima em termos quantitativos (número de agricultores e área de produção), incomoda tanto? Talvez sejam justamente seus princípios, sua multidimensionalidade e seu potencial de contribuição para mudanças sociais profundas.

A Apresentação do dossiê procura desconstruir alguns argumentos utilizados contra os alimentos orgânicos e a agroecologia. Seus cinco artigos, discutem questões teóricas, conceituais e práticas, com destaque para dois expoentes da luta pelo fortalecimento da agroecologia no Brasil: Ernst Götsch e Ana Primavesi.

Partindo de uma preocupação com o debate conceitual e teórico acerca do termo “agroecologia”, Luciano Z. P. Candiotto resgata diversos autores e documentos sobre o tema, para discutir os princípios e a multidimensionalidade da agroecologia. O artigo "Agroecologia: Conceitos, princípios e sua multidimensionalidade", também aproxima o tema da Geografia, ao dissertar sobre aspectos relacionados à multiescalaridade da agroecologia.

Ao problematizar o potencial emancipatório da agroecologia, Mariana H. M. Reinach e Guilherme A. Fabrin demonstram como a utilização do termo tem sido permeada por diferentes intencionalidades, fato que torna a agroecologia uma espécie de campo de disputa. Em "O potencial emancipatório da agroecologia em questão: Dos riscos 
de cooptação à construção da autonomia", os autores demonstram como a Organização das Nações Unidas para a Alimentação e a Agricultura (FAO) tem se posicionado com relação aos princípios da agroecologia, contrastando essa posição com perspectivas mais críticas, que têm alertado para os riscos de cooptação do termo.

Após conhecer empiricamente a Agricultura Sintrópica do suíço Ernst Götsch, Josué V. Gregio, que elaborou sua dissertação de mestrado sobre esse tema, apresenta elementos da trajetória de Götsch no Brasil, os princípios da Agricultura Sintrópica e as principais etapas para a implantação de sistemas agroflorestais sucessionais, vivenciadas nos estabelecimentos rurais da família Götsch. $\mathrm{O}$ artigo "Da degradação à floresta: A Agricultura Sintrópica de Ernst Götsch e sua aplicação nas fazendas Olhos D'Água e Santa Teresinha, Piraí do Norte/BA" sistematiza parte dos conhecimentos desenvolvidos por Ernst Götsch, através de seus experimentos e de sua busca pelo conhecimento.

Um resgate das experiências de circulação e comercialização de alimentos orgânicos, que deram origem ao Circuito Sul da Rede Ecovida de Agroecologia, é feito no artigo "A Ecoterra e seu constructo territorial de mercado: As experiências de venda direta como antecedentes do Circuito Sul de circulação e comercialização de produtos agroecológicos, criado no contexto da rede Ecovida de Agroecologia". Escrito pelo pesquisador universitário Márcio F. Eduardo (UFFS, Erechim/RS) e pelos assessores em agroecologia Edson J. Klein e Giovani J. Gonçalves, do Centro de Tecnologias Alternativas Populares (CETAP), do Rio Grande do Sul, o artigo historiciza a organização de agricultores e técnicos para viabilizar o escoamento de alimentos agroecológicos, reduzindo perdas e ampliando rendas. A experiência relatada foi o embrião do Circuito Sul, que tem otimizado a circulação de alimentos entre os estados do Rio Grande do Sul, Santa Catarina e Paraná, incluindo ainda o município de Barra do Turvo, em São Paulo.

Outra figura icônica da agroecologia, que também é objeto de um dos artigos deste dossiê, é Ana Maria Primavesi. Com sua trajetória acadêmica vinculada à compreensão da dinâmica dos solos tropicais e sua paixão e respeito pelos ciclos da natureza, o artigo "A importância do conhecimento e do manejo biológico do solo tropical para a agro- 
ecologia sob a perspectiva de Ana Maria Primavesi”, escrito pela geógrafa Virgínia M. Knabben, retrata parte de seu pensamento e de sua contribuição para a agroecologia enquanto ciência. Com base em uma relação pessoal e profissional com Primavesi, Virgínia tem sistematizado e propagado seu legado, através do site <anaprimavesi.com.br>.

Os demais artigos deste número contribuem para os seguintes temas: política ambiental brasileira; organização e resistência de indígenas Terena; e aspectos relacionados à gestão de unidades de conservação.

Em “(Des)construção da gestão ambiental no Brasil: De Paulo Nogueira Neto (1973) a Ricardo Salles (2020)", Paulo P. Gusmão e Bianca B. M. Pavão traçam uma espécie de linha do tempo no tocante às políticas de gestão ambiental no Brasil, destacando dois períodos: 1) de 1973 a 2010, com ênfase no trabalho de construção realizado por Paulo Nogueira Neto, entre 1973 e 1985; 2) de 2010 a 2020, em que os dois últimos anos (2019 e 2020) marcam o processo de desconstrução promovido por Ricardo Salles, atual Ministro do Meio Ambiente do governo Jair Bolsonaro.

Ao abordar, especificamente, os retrocessos atuais em relação à flexibilização do processo de licenciamento ambiental no Brasil, Eduardo A. S. Barcelos também discute como o atual governo federal, com amplo apoio da Câmara dos Deputados e do Senado Federal, tem efetivado um desmonte da regulação ambiental no país, considerando as relações de poder e estratégias institucionais envoltas nesse processo. Assim, junto com o trabalho de Paulo Gusmão e Bianca Pavão, o artigo "Desregulação ambiental e disputas políticas: uma breve retrospectiva do desmonte do licenciamento ambiental no Brasil" se apresenta como uma importante contribuição de registro e análise da gravidade da situação em matéria de políticas públicas no Brasil, que, certamente, tem se manifestado na expansão da degradação ambiental.

Como reflexo da inação do Estado ou, de forma mais nefasta, de uma necropolítica do Estado frente aos povos indígenas, Cerizi F. Fialho e Gislaine C. Monfort relatam a importância da auto-organização de povos da etnia Terena para combater as consequências da COVID-19 e a degradação ambiental em seus territórios. Assim, o artigo “Poké'exa 
ûti: Territorialidades de resistência Terena e auto-organização contra a pandemia e a degradação ambiental" discute como os indígenas de sete aldeias do território Indígena Taunay/Ipegue, localizado no município de Aquidauana/MS, têm resistido ao descaso e aos ataques promovidos pelo Estado e por sujeitos vinculados ao agronegócio.

O último artigo deste número versa sobre a institucionalização de processos de planejamento participativo em Unidades de Conservação no Brasil através de Conselhos Gestores, e discute, com base na criação das Áreas de Proteção Ambiental (APAs) Cabreúva, Cajamar e Jundiaí (CCJ), situadas na Serra do Japi/SP, os limites do planejamento ambiental participativo. Ao relatar as dificuldades da gestão ambiental participativa da Serra do Japi, a discussão sobre a gestão compartilhada das APAs Cabreúva, Cajamar e Jundiaí e a proposta da criação de um parque estadual na região, o artigo "A Área de Proteção Ambiental vai virar Parque? Serra do Japi e os limites do planejamento ambiental participativo", de Ricardo Silveira Orlando, problematiza elementos de planejamento e de gestão ambiental em Unidades de Conservação.

Outra grande contribuição relacionada à política e à gestão ambiental brasileiras, com ênfase na Amazônia, está na entrevista "O Brasil sofre com uma 'guerra ideológica' contra todos os que estão comprometidos contra a destruição da Amazônia", concedida por Gerd Kohlhepp, da Universidade de Tübingen (Alemanha), a Marcelo Lopes de Souza. Com base em uma vasta experiência de estudos no Brasil, Kohlhepp traça um rico panorama da destruição ambiental em nosso país, sobretudo no bioma amazônico.

Por fim, Marcelo Lopes de Souza faz uma resenha crítica da coletânea "The Palgrave Handbook of Critical Physical Geography", organizada por Rebecca Lave, Christine Biermann e Stuart N. Lane, publicada em 2019. Discutindo pormenorizadamente seus conteúdos, Souza aponta virtudes e limitações dessa obra, composta por 26 capítulos - uma obra sem dúvida relevante e marcante, mas também marcada por uma perspectiva (contraditoriamente) eurocêntrica, entre outros problemas que caracterizam a chamada "Geografia Física Crítica" em sua versão anglo-saxônica atual. 